\title{
Recent Research Advances in Dye-Sensitized Solar Cells
}

\section{Yong Soo Kang}

Center for Next Generation Dye-sensitized Solar Cells and WCU Department of Energy Engineering, Hanyang University, Seongdong-gu, Seoul 133-791, Korea

+82-2-2220-2336 (phone), +82-2-2296-2969 (fax) and kangys@hanyang.ac.kr

Dye-sensitized solar cells (DSSCs) have attracted considerable interest because of their reasonably high efficiency with low production cost. The Center for Next Generation Dye-sensitized Solar Cells, timely established in 2008 by government support, has exerted diverse efforts to improve the efficiency and to help understand the fundamentals of DSSCs. Typical examples are 1. new photoanode architecture to improve the electron transport through nanoparticular $\mathrm{TiO}_{2}$ layer, 2. highly efficient $\mathrm{SnO}_{2}$ photoanode resulted from various morphologies with simple microwave technology, 3. oligomeric co-adsorbent to suppress the electron recombination through interfaces, 4. graphene counter electrode to enhance the photocatalytic activity, and 5. novel redox mediators to improve the energy conversion efficiency. In this presentation, such new findings for the Center will be introduced briefly. 